\title{
Breastfeeding Performance Among Potentially Depressed Nursing Mothers
}

\author{
Azniah Syam ${ }^{1}$, Imelda Iskandar ${ }^{2} \&$ Erna Kadrianti $^{1}$ \\ ${ }^{1}$ Nursing Department, Sekolah Tinggi Ilmu Kesehatan Nani Hasanuddin Makassar, South Sulawesi, Indonesia \\ ${ }^{2}$ Midwife Department, Akademi Kebidanan Yapma Makassar, South Sulawesi, Indonesia \\ Correspondence: Azniah Syam, Nursing Department, Sekolah Tinggi Ilmu Kesehatan Nani Hasanuddin \\ Makassar, South Sulawesi, Indonesia. E-mail: azniahsyam@gmail.com
}

Received: October 9, 2019 Accepted: October 28, 2019 Online Published: November 5, 2019

doi:10.5539/gjhs.v11n13p59

URL: https://doi.org/10.5539/gjhs.v11n13p59

\begin{abstract}
Background: The maternal process is vulnerable for women to fall in an anxiety state that refers to postpartum depression. When symptoms appear, the possibility of depression during pregnancy will have a direct impact on the initiation of early breastfeeding and the termination of early breastfeeding.

Purposes: This study aims to look at the relationship between the potential of postpartum depression and the performance of breastfeeding in nursing mothers. This study used a cross-sectional study approach, in one of the sub-districts in Makassar City with the lowest achievement of exclusive breastfeeding.

Methods: The study subjects were postpartum mothers who fulfilled 225 eligibility sampling throughout the period March-August 2018. Sociodemographic, social support, obstetric variables, potential maternal postpartum depression, and breastfeeding performance assessment were collected and analyzed using the chi-square test and independent-sample t-test.

Results: The study show that age $(<0.001)$, work profile $(<0.001)$, living property $(<0.006)$, number of children $(<0.001)$, and family support $(<0.001)$ have been shown to influence maternal depression.

Conclusion: This study conclude that sociodemographic factors, especially economic vulnerability and social support, are risk factors for depression in nursing mothers. Although it did not appear to be different from breastfeeding performance between mothers who experienced depressive symptoms and anxiety, both felt the same of the obstacles to breastfeeding techniques. Therefore, this study recommend for all mother and child services to performed screening for depression symptom in term of pregnancy, and provide them skill for better lactation.
\end{abstract}

Keywords: postpartum, depression, risk factors, breastfeeding

\section{Introduction}

Postpartum depression is a sedentary situation in new women in the form of affective disorders, decreased mood, feelings of sadness, worthlessness, despair, and tends to last four to six weeks (American Psychiatric Association, 2013; Americans et al., 2013). Clinical symptoms of postpartum depression are similar to depression generally in a woman's life cycle, but physiologically the symptoms begin during pregnancy and childbirth (O'Hara \& Wisner, 2014). This situation usually preceded by baby blues syndrome, experienced by 4 out of 5 women on the first day until the tenth day since the baby is born (Heron, Haque, Oyebode, Craddock, \& Jones, 2009). Symptoms of postpartum depression are sometimes followed by eating, sleeping, and fatigue, making it difficult to distinguish between clinical and physical symptoms to measure its onset. However, in one review study confirmed psychological symptoms manifested in the form of anxiety triggered depression (Biaggi, Conroy, Pawlby, \& Pariante, 2016).

When compared with depression commonly in women, postpartum depression has a high risk of obsessive-compulsive comorbid disorders (Russell, Fawcett, \& Mazmanian, 2013) and anxiety (Biaggi et al., 2016; Heron et al., 2009). The most dangerous consequences are the emergence of a desire to self-harm or the baby, even suicidal ideation (Wisner et al., 2013). If this situation untreated immediately, the possibility to grow into psychosis that harms all family members, although the chances are only 2 out of 1000 live births (Ganjekar, Desai, 
\& Chandra, 2013). This worsening of psychological problems requires care and rehabilitation. Most end up with an imperfect functional recovery rate (Biaggi et al., 2016). Postpartum depression also has a long-term impact on aspects of growth and development, emotional, cognitive, physical, behavioral, and decreased intelligence in school-age children (Field, 2010; Korhonen, Luoma, Salmelin, \& Tamminen, 2012). Bonding between mother and baby is weak and has the potential to form violent parenting (Biaggi et al., 2016).

In Indonesia, the prevalence of postpartum depression reports unclear, by this mean postpartum depression retain in low priority among public health problems that requiring intervention. The individual situation of either women or mothers is generally unaware of changes in mood, anxiety, despair that accompany changes in the physiology of pregnancy and childbirth as a problem in the frame of depression. The word "depression" is a stigma that closer to the term "crazy." So that it is not easily detected because it hides sometimes. It takes foresight of midwives to observe these symptoms since antenatal care so that mothers want to be open and share information. For that, we need a simple measuring instrument as a screening tool. One quantitative measure designed to detect possible depression is the Edinburgh Postnatal Depression Scale (EPDS). In the form of a questionnaire containing ten questions about the feelings of mothers in the past week. This instrument applies in various countries, and the results are valid and reliable. This measuring device is simple, easy to calculate by health workers, quick to work on, more comfortable on the patient's side, language easy to understand, and relatively little cost. EPDS validates in the Indonesian version in 2006, with a sensitivity level of 91.7 and specificity of 76.9 (Edwards et al., 2006).

When symptoms appear, the possibility of depression during pregnancy will have a direct impact on the initiation of early breastfeeding and the termination of early breastfeeding. Physiologically, milk production is regulated by hormonal mechanisms that are very sensitive to the psychological response of the mother. Anxiety is one of the symptoms of postpartum depression has an inhibitory effect on the release of the hormone oxytocin and prolactin. Continuous effects will interfere with the reflex of milk production and production (Dewey, 2001). Several studies report that breastfeeding mothers have a higher chance of depression (Alder, 1988; Groër, 2005), while other studies reveal that formula feeding has a higher risk of depression compared to breastfeeding mothers.

The relationship between breastfeeding and postpartum depression is bidirectional. A depressed pregnant woman is less likely to intend to breast-feed her infant (Biaggi et al., 2016), to initiate (Russell et al., 2013) or to maintain breastfeeding during the postpartum period (Wisner et al., 2013). Literature reviews suggest that breastfeeding is also less common among postpartum depressed mothers(Ganjekar et al., 2013). Whether postpartum maternal depression may cause early cessation of breastfeeding, and depressive symptoms have been noted to precede breastfeeding cessation as was noticed by some reviewers (Field, 2010), or it merely results from cessation of breastfeeding as proved by others, who noticed the stoppage of lactation precedes the appearance of depression (Korhonen et al., 2012). The prevalence of exclusive breastfeeding in mothers who have experienced postpartum depression tends to be very low (B. Figueiredo, Canário, \& Field, 2014; Bárbara Figueiredo \& Conde, 2011), the ability to maintain the lactation period is also getting weaker (Field, 2010), while mothers who do not initiate early breastfeeding and breast milk tend to be more prone to depression during lactation (Hamdan \& Tamim, 2012). Therefore, this study aims to detect differences in postpartum depression events from the sociodemographic, social support, obstetric, and breastfeeding performance variable.

\section{Methods}

This study used an observational design with a cross-sectional study approach. The study conducted in one of the Subdistrict areas, Makassar City, with the lowest achievement of exclusive breastfeeding in the last three years. The subjects of the study were postpartum mothers with criteria for spontaneous vaginal delivery assisted by midwives or physicians and/or ob-gyn, no previous history of depression, no smoking, and never consuming alcoholic beverages. The number of research subjects that became the target population was all mothers breastfeeding infants aged 0-12 weeks during the period March-August 2018 totaling 275 mothers, but those who met the inclusion criteria were only 225 mothers. Data collection was in the form of sociodemographic data (maternal age at marriage and delivery, education, employment, family economic status, residence status, family structure), obstetric data (parity and age), family support, assessment of breastfeeding effectiveness, and maternal postpartum depression carried out during postpartum visits by midwives according to the time period of the visit scheduled for each mother. Sociodemographic and obstetric data were collected using a confirmed observation sheet with a medical record of maternal labor history from the clinic, breastfeeding performance data using the UNICEF Breastfeeding-Aid 2009 sheet, and depression data measured by Edinburgh Postnatal Depression Scale. The family support measured by 10 items likert-scale questionnaire regarded to husband's support given during pregnancy, childbirth, and breastfeeding. The entire process of data collection was carried out by seven standardized enumerators (training in the standardization of measurement methods and research data collection) 
through the interview process. To measure the correlation between sociodemographic, obstetric, postpartum depression variables on the performance of the breastfeeding process using the chi-square statistical test for nominal data and independent $t$-test for numerical data.

\section{Results}

To distinguish between the group, ten cut off point is selected according to the reference of the Indonesian translated version (Cox, Holden, \& Sagovsky, 1987). All item in EPDS during validity and reliability tested, the EPDS instrument is reliable as shown (table 2) with Cronbach Alpha 0.706, except for validity item \#1 and 2. In both groups divided by scores above and equal/below 10 . According to table 1, almost $15 \%$ chose the larger scale, except for enjoyment, unhappy and crying, and harming self. It shows that during pregnancy and the postpartum period, mothers tend to form an anhedonia and anxiety feeling. While in severe cases show destructive depression sign as harming herself and baby, even suicide thought.

Tabel 1. Highest depression scale item analysis

\begin{tabular}{|c|c|c|c|c|}
\hline \multirow{2}{*}{ No } & \multirow{2}{*}{ Item } & \multirow{2}{*}{$\begin{array}{l}\text { Depression } \\
\mathrm{n}\end{array}$} & \multirow{2}{*}{$\begin{array}{c}\text { Highest Scale } \\
\%\end{array}$} & \multirow{2}{*}{ Corrected item-total correlation } \\
\hline & & & & \\
\hline 1 & Unable to laugh & 38 & 16.9 & 0.067 \\
\hline 2 & Lack of enjoyment & 3 & 1.3 & 0.111 \\
\hline 3 & Self-blame unnecessarily & 34 & 15.1 & 0.579 \\
\hline 4 & Been anxious or worried & 37 & 16.4 & 0.419 \\
\hline 5 & Been scared or panicky & 30 & 13.3 & 0.554 \\
\hline 6 & Things have been getting on top of me & 43 & 19.1 & 0.294 \\
\hline 7 & Difficulty sleeping & 33 & 14.7 & 0.611 \\
\hline 8 & Felt sad or miserable & 25 & 11.1 & 0.430 \\
\hline 9 & So unhappy that have been crying & 16 & 7.1 & 0.298 \\
\hline 10 & Thought of harming self & 5 & 2.2 & 0.380 \\
\hline
\end{tabular}

$p$-value $<0.131$ (Pearson Correlation), $\mathrm{df}=223$.

Table 2, shows the results of the bivariate analysis of several observed risk factors, including sociodemographic, family support, obstetric factors. Marriage age factors (Table 1) did not reveal a significant difference between depression scores $>10$ and $\leq 10$, in both groups, there was a similar tendency that mothers married at the age of 20 years, but pregnancy-related age proved to be significant on the results of measuring the scale of depression. Similarly, the number of children is proven to be one of the risk factors for depression. Working mothers appear to be more anxious while a household mother has the potential to experience more significant depression. Having a permanent residence in one of the risk factors for depression, but not with the number of family members living together. Family support in this study showed a significant relationship to the possibility of depression while family income and education levels are not proven to be risk factors for postpartum depression. The mean score in depression score $\leq 10$ are higher than in depression score $>10$. This stated that the more often husband giving their personal support to their couples, the lower their potential to suffer from depression. 
Table 2. Risk factor of depression

\begin{tabular}{|c|c|c|c|c|c|}
\hline \multirow{4}{*}{ Variable } & \multirow{3}{*}{\multicolumn{2}{|c|}{$\begin{array}{l}\text { Depression Score } \\
>10 \\
n=113\end{array}$}} & \multirow{3}{*}{\multicolumn{2}{|c|}{$\begin{array}{l}\text { Depression Score } \\
\leq 10 \\
n=112\end{array}$}} & \multirow{4}{*}{ P Value } \\
\hline & & & & & \\
\hline & & & & & \\
\hline & $\mathrm{n}$ & $\%$ & $\mathbf{n}$ & $\%$ & \\
\hline \multicolumn{6}{|l|}{ Education } \\
\hline Undergraduated & 93 & 50.0 & 93 & 50.0 & \multirow[t]{2}{*}{0.884} \\
\hline Graduated & 20 & 51.3 & 19 & 48.7 & \\
\hline \multicolumn{6}{|l|}{ Work Profile } \\
\hline Household & 90 & 64.3 & 50 & 35.7 & \multirow[t]{2}{*}{0.001} \\
\hline Employee & 23 & 27.1 & 62 & 72.9 & \\
\hline \multicolumn{6}{|l|}{ Family Income } \\
\hline$<$ Regional Minimum Wage & 75 & 51.7 & 70 & 48.3 & \multirow[t]{2}{*}{0.544} \\
\hline$\geq$ Regional Minimum Wage & 38 & 47.5 & 42 & 52.5 & \\
\hline \multicolumn{6}{|l|}{ Living Property } \\
\hline Own House & 44 & 40.7 & 64 & 59.3 & \multirow[t]{2}{*}{0.006} \\
\hline Rent & 69 & 59.0 & 48 & 41.0 & \\
\hline \multicolumn{6}{|l|}{ Family Structure } \\
\hline Nuclear & 57 & 57.6 & 42 & 42.4 & \multirow[t]{2}{*}{0.051} \\
\hline Extended & 56 & 44.4 & 70 & 55.6 & \\
\hline \multicolumn{6}{|l|}{ Family Support } \\
\hline Mean (SD) & \multicolumn{2}{|c|}{$32.32( \pm 7.172)$} & \multicolumn{2}{|c|}{$36.48( \pm 7.131)$} & 0.001 \\
\hline \multicolumn{6}{|l|}{ Breastfeeding Performance } \\
\hline Mean (SD) & \multicolumn{2}{|c|}{$17.50( \pm 2.758)$} & \multicolumn{2}{|c|}{$16.98( \pm 2.697)$} & 0.130 \\
\hline \multicolumn{6}{|l|}{ Mothers Age } \\
\hline Mean (SD) & \multicolumn{2}{|c|}{$25.26( \pm 6.677)$} & \multicolumn{2}{|c|}{$28.29( \pm 5.715)$} & 0.001 \\
\hline \multicolumn{6}{|l|}{ Mother Marriage Age } \\
\hline Mean (SD) & \multicolumn{2}{|c|}{$20.58( \pm 4.317)$} & \multicolumn{2}{|c|}{$20.78( \pm 3.915)$} & 0.691 \\
\hline \multicolumn{6}{|l|}{ Parity } \\
\hline Mean (SD) & \multicolumn{2}{|c|}{$1.52( \pm 0.669)$} & \multicolumn{2}{|c|}{$2.21( \pm 1.350)$} & 0.001 \\
\hline \multicolumn{6}{|l|}{ Babies Age } \\
\hline Mean (SD) & \multicolumn{2}{|c|}{$3.09( \pm 3.605)$} & 2.95 & & 0.641 \\
\hline
\end{tabular}

According to reliability and validity testing, there are four items not valid (item $\# 7,8,9,14$ ), therefore we removed all four items. The breastfeeding performance instrument contains 22 items consisting five different dimensions including the general condition of mothers and baby (item \#1-6), breast appearance (item \#7-10), baby positions (item \#11-14), attachment (item \#15-18), and suckling (item \#19-22), The Cronbach Alpha 0.571. The breast appearance assessment on items \#7, 8, 9, more likely needed an expert to examine, while the enumerator is not well trained for the field. Different from items \#10, the breastfeeding process clear enough to observe by none expert data observer. After removing all unvalid items, we running test on chi-square test as shown on Table 2. 
Tabel 3. Difficulties in breastfeeding performance item

\begin{tabular}{|c|c|c|c|c|c|}
\hline \multirow{2}{*}{ No } & \multirow{2}{*}{ Breastfeeding Observation Items } & \multicolumn{2}{|c|}{ Depression Score $>\mathbf{1 0}$} & \multicolumn{2}{|c|}{ Depression Score $\leq 10$} \\
\hline & & $\mathbf{n}$ & $\%$ & $\mathbf{n}$ & $\%$ \\
\hline 1 & Mother looks healthy* & 3 & 2.7 & 3 & 2.7 \\
\hline 2 & Mother relaxed and comfortable* & 6 & 5.3 & 5 & 4.5 \\
\hline 3 & Signs of bonding between mother and baby* & 55 & 48.7 & 63 & 56.3 \\
\hline 4 & Baby looks healthy & 2 & 1.8 & 6 & 5.4 \\
\hline 5 & Baby calm and relaxed & 20 & 17.7 & 25 & 22.3 \\
\hline 6 & Baby reaches or roots for breast if hungry & 14 & 11.5 & 17 & 15.2 \\
\hline 7 & Breasts look healthy* & 2 & 1.8 & 0 & 0.0 \\
\hline 8 & Nipple protractile $(+)$, nipple flat $(-)^{*}$ & 3 & 2.7 & 0 & 0.0 \\
\hline 9 & No pain or discomfort* & 9 & 8.0 & 14 & 12.5 \\
\hline 10 & Breast well supported with fingers away from the nipple & 36 & 31.9 & 35 & 31.3 \\
\hline 11 & Baby's head and body inline & 13 & 11.5 & 21 & 18.8 \\
\hline 12 & Baby held close to the mother's body & 26 & 23.0 & 20 & 17.9 \\
\hline 13 & Baby's whole body supported & 53 & 46.9 & 53 & 47.3 \\
\hline 14 & Baby approaches to breast, nose to nipple* & 19 & 16.8 & 18 & 16.1 \\
\hline 15 & More areola saw above baby's top lip & 13 & 11.5 & 19 & 17.0 \\
\hline 16 & Baby's mouth open wide* & 7 & 6.2 & 18 & 16.1 \\
\hline 17 & Lower lip turn outwards* & 15 & 13.3 & 31 & 27.7 \\
\hline 18 & Baby's chin touches breast* & 17 & 15.0 & 40 & 35.7 \\
\hline 19 & Slow, deep suck with pauses & 61 & 54.0 & 50 & 44.6 \\
\hline 20 & Cheeks round when suckling & 58 & 51.3 & 57 & 50.9 \\
\hline 21 & Baby releases breast when finished* & 38 & 33.6 & 29 & 25.9 \\
\hline 22 & The mother notices signs of oxytocin reflex* & 36 & 31.9 & 39 & 34.8 \\
\hline
\end{tabular}

*Items difficulties in both groups that indicate significance problem.

Even though in this research failed to accept the significant correlation between breastfeeding performance and depression, but several difficulties (Table 3) issued same in both groups such as bonding between mothers and baby, restless and crying baby, the steps in positioning babies towards breast and persistence attachment and suckling until breastfeeding process terminated.

\section{Discussion}

The prevalence of depression and anxiety in the pre and postnatal period in developed countries is in the range of less than 20\% (Anderson, Hatch, Comacchio, \& Howard, 2017). However, the potential for depression in the post-partum period is far higher than the prenatal period. Whereas in developing countries, the prevalence of depression is above $20 \%$. Depression in developing countries tends not to be detected properly because awareness of women and health workers is generally different (Gavin et al., 2005). Sticky depression with a negative connotation, so it is hidden or even considered normal. Many cases reported in the media, such as mothers who kill their children are considered to be due to economic burdens, even though in fact, there may be profound depressive symptoms escaped observation (Evans, 2006; Ross, Evans, Sellers, \& Romach, 2003).

In this study, out of 225 post-partum mothers, more than $50 \%$ experienced signs and symptoms of depression, household mothers faced more symptoms of depression than working mothers. This possible because of the increase in workload during postpartum at home. The role of mothers in caring for babies is generally done alone because it considers as a women's responsibility, whereas the role as a housewife with household routine duties remains her responsibility. Fatigue is also one of the causes of anxiety and depression (Kawano \& Emori, 2015). Most of the subjects studied were mothers with middle to lower welfare standards, which meant that they were 
mostly unable to finance a maid, so all of the work chores were done on their own. This study shows that household mothers have enormous potential for depression than working mothers.

Literature review in Korea found that employment status and low income significantly correlated with prenatal depression in the first trimester. The average depression score in the first trimester $(\mathrm{p}<0.04)$ and second $(\mathrm{p}<0.04)$ differed significantly from household income. In particular, women with a monthly income of $\$ 2,000$ e $\$ 3,000$ were significantly more depressed in the first and second trimesters than women in the other two monthly income groups (Park, Karmaus, \& Zhang, 2015). Low-income women are especially at high risk for postpartum depression. Prevalence of postpartum depression among low-income mothers between three and nine months after giving birth, count from $33 \%$ to nearly $40 \%$ (Kim et al., 2012).

Housing or home is also one of the issues in the sociodemographic aspect. Having a private house for industrial standards in a big city is not easy. Those who have a family have children but still live in a rental house have the possibility of a more vulnerable depression. Based on the description of the data, mothers with a higher number of family members living together in one house show a higher likelihood of depression than those who only live with their husbands and children, especially for families whose status is still hitching or living with parents or in-laws. Sometimes the independence in making decisions influence how strong the pressure and dominance of her parents-in-law or parents. This vulnerability will increase, mostly in pregnancy and is more severe in the first pregnancy. Based on research conducted in China, boys are closely related to their original families and naturally are more likely to support their parents in conflict-in-law (Norhayati, Nik Hazlina, Asrenee, \& Wan Emilin, 2015). Therefore, we speculate that the increased risk of PPD (Postpartum Depression) for postpartum women who live with their in-laws may be due to poor marital relationships caused by conflict-in-law. The results showed that OR or 95\% CI PPD were not adjusted and multivariate based on whether postpartum women lived with their parents or with their in-laws. Compared to those who only lived with their husbands, postpartum women living with their in-laws had a higher risk of PPD (OR $=1.50 ; 95 \%$ CI: 1.02, 2.23) in an unadjusted model (Park et al., 2015).

Pregnancy events distinguished by different physiological changes and adaptations for each woman. It is influenced by nutritional status and age at the time the mother is pregnant. Based on the results of the study of mothers with young age, on average 25 years and under, it is more likely to experience symptoms of depression, followed by the number of children. Multipara tends to have a lower EPDS score, that means pregnancy events also have a value of psychological learning. The experience of parenting gives the mother the confidence to perceive her ability to do the right thing, or just the adaptive ability of the emotional changes that occur from previous experiences. The sociodemographic characteristics of the study participants indicated that there was a statistically significant difference in the age of $<25$ years having twice the risk of postpartum depression compared to $>25$ years (Norhayati et al., 2015).

Social support, especially from husbands, is essential; it cannot deny that the task of becoming a parent is not only mother responsibility. The involvement of fathers in providing simple assistance, the presence of husbands in each phase of pregnancy, childbirth, and breastfeeding makes the mother feel comfortable with funds. A calm feeling helps erratic emotional stability, especially when breastfeeding. Extensive study proof that fathers become the most critical role in helping breastfeeding successful. According to a recent study in Indonesia, to enable the father to support their couple to breastfed more, they need to understand the importance of breastfeeding. They also need more time to the side by side with mother, therefore working father must pay more extended paternity leave, and this awareness must take into legitimate public policy (Rahadian, 2018). According to World Breastfeeding Week (WBW), this year, the campaign coming to theme Empower Parents Enable Breastfeeding. Breastfeeding is mother domain, but when all supporting system, fathers, family partner, workplace, environment, and community support, the breastfeeding rates and quality improves.

Although in this study, it failed to prove several other risk factors related to depression, especially the breastfeeding process. However, some barriers to breastfeeding seem to be felt by most mothers. As mentioned earlier that, even in both groups shown no significant difference in performing breastfeeding, but among items observation during breastfeeding process, indicate moderate difficulties in the persistence of bonding between mothers and baby during breastfeeding time. Therefore, the baby becomes restless and crying. Most new mothers are having an issue with the crying baby. Sometimes crying can derive the mother anxious feeling. However, on the other circumstances, crying baby is resulting from poor positioning and suckling during attachment as performing on both groups item 10 to 14 generating steps in positioning the newborn baby. The most considerable difficulty in positioning is in supporting the whole newborn body. Inadequate positioning and attachment recreate in optimal sucking. In this situation, the baby will not satisfy with breastfeeding and back to more restless and crying behavior. 


\section{Conclusion}

This study concluded that parity, mothers age, working profile, family support and family income are related to postpartum depression. This study failed to prove significant difference in breastfeeding performance score between depressed and non-depressed mother, but this study found several similar difficulties experienced by both are related to whole important part of breastfeeding process.

This study recommended to reduce the burden caused by barriers of breastfeeding, pregnant mothers need to hold on better lactation skills before they gave birth. Mother and child services should also consider to provide essential screening mechanism for potential symptoms of depression regarding to other five risk factors that showed significance correlation to postpartum depression.

\section{Acknowledgments}

We would like to express our gratitude to the ministry of Higher Education, Research and Technology of The Indonesian Government for supporting this research to be presented in $19^{\text {th }}$ International Conference on Bio-Medical Science. We also thank all the woman in this study over her willingness to share their personal life with us to improve our knowledge in understanding breastfeeding and depression. Last, to all of our outstanding midwife student who spent their full time helping us to collect data. To all primary health care midwife, nurse, nutritionist, for the cooperative work field.

\section{Competing Interests Statement}

The authors declare that there are no competing or potential conflicts of interest.

\section{References}

Alder, E. (1988). The relationship between breast feeding persistence, sexuality and mood in postpartum women. Psychological Medicine. https://doi.org/10.1017/S0033291700007935

American Psychiatric Association. (2013). Diagnostic and Statistical Manual of Mental Disorders. Arlington. https://doi.org/10.1176/appi.books.9780890425596.744053

Americans, N., Article, S., Haghir, H., Mokhber, N., Azarpazhooh, M. R., Haghighi, M. B., ... World Health Organization. (2013). The ICD-10 Classification of Mental and Behavioural Disorders. IACAPAP E-Textbook of Child and Adolescent Mental Health. https://doi.org/10.4103/0019

Anderson, F. M., Hatch, S. L., Comacchio, C., \& Howard, L. M. (2017). Prevalence and risk of mental disorders in the perinatal period among migrant women: a systematic review and meta-analysis. Archives of Women's Mental Health, 20(3), 449-462. https://doi.org/10.1007/s00737-017-0723-z

Biaggi, A., Conroy, S., Pawlby, S., \& Pariante, C. M. (2016). Identifying the women at risk of antenatal anxiety and depression: A systematic review. Journal of Affective Disorders. https://doi.org/10.1016/j.jad.2015.11.014

Cox, J. L., Holden, J. M., \& Sagovsky, R. (1987). Detection of Postnatal Depression. British Journal of Psychiatry, 150(6), 782-786. https://doi.org/10.1192/bjp.150.6.782

Dewey, K. G. (2001). Maternal and fetal stress are associated with impaired lactogenesis in humans. The Journal of Nutrition. https://doi.org/10.1093/jn/131.11.3012S

Edwards, G., Shinfuku, N., Gittelman, M., Ghozali, E., Haniman, F., Wibisono, S., .. Rappe, P. (2006). Postnatal Depression in Surabaya, Indonesia. International Journal of Mental Health. https://doi.org/10.2753/IMH0020-7411350105

Evans, G. W. (2006). Child Development and the Physical Environment. Annual Review of Psychology, 57(1), 423-451. https://doi.org/10.1146/annurev.psych.57.102904.190057

Field, T. (2010). Postpartum depression effects on early interactions, parenting, and safety practices: A review. Infant Behavior and Development. https://doi.org/10.1016/j.infbeh.2009.10.005

Figueiredo, B., Canário, C., \& Field, T. (2014). Breastfeeding is negatively affected by prenatal depression and reduces postpartum depression. Psychological Medicine. https://doi.org/10.1017/S0033291713001530

Figueiredo, Bárbara, \& Conde, A. (2011). Anxiety and depression symptoms in women and men from early pregnancy to 3-months postpartum: Parity differences and effects. Journal of Affective Disorders. https://doi.org/10.1016/j.jad.2011.02.007

Ganjekar, S., Desai, G., \& Chandra, P. S. (2013). A comparative study of psychopathology, symptom severity, and 
short-term outcome of postpartum and nonpostpartum mania. Bipolar Disorders. https://doi.org/10.1111/bdi.12076

Gavin, N. I., Gaynes, B. N., Lorh, K. N., Meltzer-Brody, S., Gartlehner, G., \& Swinson, T. (2005). Perinatal depression: a systematic review. Obstetrics and Gynecology, 106(5), 1071-1083. https://doi.org/10.1097/01.AOG.0000183597.31630.db

Groër, M. W. (2005). Differences between exclusive breastfeeders, formula-feeders, and controls: A study of stress, mood, and endocrine variables. Biological Research for Nursing. https://doi.org/10.1177/1099800405280936

Hamdan, A., \& Tamim, H. (2012). The Relationship between Postpartum Depression and Breastfeeding. The International Journal of Psychiatry in Medicine. https://doi.org/10.2190/PM.43.3.d

Heron, J., Haque, S., Oyebode, F., Craddock, N., \& Jones, I. (2009). A longitudinal study of hypomania and depression symptoms in pregnancy and the postpartum period. Bipolar Disorders. https://doi.org/10.1111/j.1399-5618.2009.00685.x

Kawano, A., \& Emori, Y. (2015). The Relationship Between Maternal Postpartum Psychological State and Breast Milk Secretory Immunoglobulin A Level. Journal of the American Psychiatric Nurses Association. https://doi.org/10.1177/1078390314566882

Kim, H. G., Geppert, J., Quan, T., Bracha, Y., Lupo, V., \& Cutts, D. B. (2012). Screening for postpartum depression among low-income mothers using an interactive voice response system. Maternal and Child Health Journal, 16(4), 921-928. https://doi.org/10.1007/s10995-011-0817-6

Korhonen, M., Luoma, I., Salmelin, R., \& Tamminen, T. (2012). A longitudinal study of maternal prenatal, postnatal and concurrent depressive symptoms and adolescent well-being. Journal of Affective Disorders. https://doi.org/10.1016/j.jad.2011.10.007

Norhayati, M. N., Nik Hazlina, N. H., Asrenee, A. R., \& Wan Emilin, W. M. A. (2015). Magnitude and risk factors for postpartum symptoms: A literature review. Journal of Affective Disorders. https://doi.org/10.1016/j.jad.2014.12.041

O’Hara, M. W., \& Wisner, K. L. (2014). Perinatal mental illness: Definition, description and aetiology. Best Practice and Research: Clinical Obstetrics and Gynaecology. https://doi.org/10.1016/j.bpobgyn.2013.09.002

Park, J. H., Karmaus, W., \& Zhang, H. (2015). Prevalence of and risk factors for depressive symptoms in Korean women throughout pregnancy and in postpartum period. Asian Nursing Research, 9(3), 219-225. https://doi.org/10.1016/j.anr.2015.03.004

Rahadian, A. S. (2018). How can father breastfeed? Asking Ayah in Jakarta, Indonesia. The University of Waikato. Retrieved from https://researchcommons.waikato.ac.nz/bitstream/handle/10289/12376/thesis.pdf? sequence= 4\&isAllowed $=\mathrm{y}$

Ross, L. E., Evans, S. E. G., Sellers, E. M., \& Romach, M. K. (2003). Measurement issues in postpartum depression part 1: Anxiety as a feature of postpartum depression. Archives of Women's Mental Health, 6(1), 51-57. https://doi.org/10.1007/s00737-002-0155-1

Russell, E. J., Fawcett, J. M., \& Mazmanian, D. (2013). Risk of obsessive-compulsive disorder in pregnant and postpartum women: A meta-analysis. Journal of Clinical Psychiatry. https://doi.org/10.4088/JCP.12r07917

Wisner, K. L., Sit, D. K. Y., McShea, M. C., Rizzo, D. M., Zoretich, R. A., Hughes, C. L., ... Hanusa, B. H. (2013). Onset Timing, Thoughts of Self-harm, and Diagnoses in Postpartum Women With Screen-Positive Depression Findings. JAMA Psychiatry, 70(5), 490. https://doi.org/10.1001/jamapsychiatry.2013.87

\section{Copyrights}

Copyright for this article is retained by the author(s), with first publication rights granted to the journal.

This is an open-access article distributed under the terms and conditions of the Creative Commons Attribution license (http://creativecommons.org/licenses/by/4.0/). 